\title{
Rapid Access Ice Drill: a new tool for exploration of the deep Antarctic ice sheets and subglacial geology
}

\author{
JOHN W. GOODGE, ${ }^{1}$ JEFFREY P. SEVERINGHAUS ${ }^{2}$ \\ ${ }^{1}$ Department of Earth and Environmental Sciences, University of Minnesota, Duluth, MN 55812, USA \\ ${ }^{2}$ Scripps Institution of Oceanography, UC San Diego, La Jolla, CA 92093, USA \\ Correspondence: John W. Goodge <jgoodge@d.umn.edu>
}

\begin{abstract}
A new Rapid Access Ice Drill (RAID) will penetrate the Antarctic ice sheets in order to create borehole observatories and take cores in deep ice, the glacial bed and bedrock below. RAID is a mobile drilling system to make multiple long, narrow boreholes in a single field season in Antarctica. RAID is based on a mineral exploration-type rotary rock-coring system using threaded drill pipe to cut through ice using reverse circulation of a non-freezing fluid for pressure-compensation, maintenance of temperature and removal of ice cuttings. Near the bottom of the ice sheet, a wireline latching assembly will enable rapid coring of ice, the glacial bed and bedrock below. Once complete, boreholes will be kept open with fluid, capped and available for future down-hole measurement of temperature gradient, heat flow, ice chronology and ice deformation. RAID is designed to penetrate up to $3300 \mathrm{~m}$ of ice and take cores in $<\mathbf{2 0 0}$ hours, allowing completion of a borehole and coring in $\sim 10 \mathrm{~d}$ at each site. Together, the rapid drilling capability and mobility of the system, along with ice-penetrating imaging methods, will provide a unique 3-D picture of interior and subglacial features of the Antarctic ice sheets.
\end{abstract}

KEYWORDS: Antarctica, bedrock coring, ice drilling, million year-old ice, subglacial access

\section{INTRODUCTION}

By many measures, Antarctica is the last continental frontier. Although more than $98 \%$ of Antarctica's geology is hidden beneath ice cover, coastal and mountain exposures demonstrate an ancient ancestry tied to early crustal growth and supercontinent evolution (Harley and others, 2013). Antarctica is also central to changing global climate patterns, both as a recorder of past changes and as a sensitive witness to changes currently underway, providing crucial motivation for future research on ice-sheet and global climate systems. Marine records and general circulation models suggest that the major ice cap of Antarctica nucleated 34 Ma (Zachos and others, 1996; DeConto and Pollard, 2003), but the interior structure of the ice sheets are poorly known and major questions remain about their expanse and persistence over time. Existing ice cores provide a paleoclimate and greenhouse-gas record reaching back $0.8 \mathrm{Ma}$, but there is very likely to be older ice that preserves a record of the enigmatic climate transition that occurred between 1.3 and $0.9 \mathrm{Ma}$ (Fischer and others, 2013; Van Liefferinge and Pattyn, 2013). In this event, known as the 'mid-Pleistocene transition', well-ordered 41 ka glacial cycles driven by orbital obliquity gave way to irregular $\sim 100$ ka glaciations whose origin is still not well understood (Raymo and others, 2006; Lisiecki and Raymo, 2007).

Knowledge derived from a variety of disciplines now points to important linkages between the solid earth, atmosphere, cryosphere and biosphere. The connected geologic, glacial and hydrologic elements of this integrated system play a critical role in global climate changes currently underway, including future sea level, and detectable changes in Antarctica provide a measure of the broader climate variation. Rock, sediment and ice all harbor critical information about past changes to the landmass, ice caps and climate system in Antarctica on a variety of timescales, but our understanding of these interdependencies is derived from only a tantalizingly small body of data. Focused study of the relationships and feedbacks between these elements is possible through multidisciplinary research in geology and geophysics, glaciology, paleoclimate and microbiology, providing a unique opportunity to better understand the temporalspatial variations and operative dynamic processes in a polar continental setting (Zapol and others, 2011). Since the time of the International Geophysical Year in 1958, scientists have pushed ever deeper into Antarctica, both across and through the major ice caps. Now, decades later, Antarctica remains a cryptic but accessible natural laboratory in which to study a polar continent and its overlying ice sheets, subglacial mountains and subglacial lakes. However, because Antarctica is $\sim 89 \%$ the area of the contiguous US and Europe combined, the vast scale offers both scientific and logistical challenges. Furthermore, a significant impediment to our understanding of dynamic change in the Antarctic earth system is our inability to quickly obtain samples at the deepest levels of the ice caps. Ice coring programs, for example, typically take several years and tens of millions of US dollars to complete.

Access to deep (therefore ancient) ice and bedrock geology over large areas of the Antarctic interior will allow scientists to address a wide range of interdisciplinary questions, including, from top to bottom:

(1) can we find $>1 \mathrm{Ma}$ ice and, if so, what paleoclimate information does it contain?

(2) what caused the switch from 41 to $\sim 100 \mathrm{ka}$ glacial cycles $1 \mathrm{Ma}$ ?

(3) what is the current dynamic behavior of the major ice caps? 
(4) how much will sea level rise in the future due to Antarctic ice loss?

(5) what are the physical conditions and material properties of the ice/rock interface?

(6) what is the subglacial landscape history?

(7) what do interior sedimentary basins tell us about longterm ice-sheet stability?

(8) is there life at the base of the ice sheets?

(9) what is the effect of subglacial heat flow on ice-sheet stability?

(10) what is nature and history of Antarctic lithosphere?

Questions such as these drive an inter-related set of goals for gaining deep access within the Antarctic ice sheets, including: (a) documenting the presence of Eemian-age ice to test models of ice-sheet collapse in West Antarctica ( 125 ka); (b) understanding the mid-Pleistocene transition from 41 to 100 ka climate cycles (by sampling ice as old as $\sim 1.5 \mathrm{Ma}$ ); (c) evaluating the thermal, mechanical and biological conditions at the base of the ice sheets; (d) exploring the deep interior geology of Antarctica for the first time, including the characterization of geophysically-imaged geological features; and (e) testing models of cratonic growth related to supercontinent assembly in the Mesoproterozoic ( $1 \mathrm{Ga})$.

To address these questions in deep ice, we need the ability to rapidly penetrate the Antarctic ice sheets in multiple locations. The concept for such a drilling technology has circulated in the science community for some time. Early ideas for fast mechanical access drilling in ice and subglacial bedrock were described by Clow and Koci (2002), but cost and technology limitations prevented their development. This paper outlines the scientific goals, guiding principles of engineering and environmental stewardship, technical design and status of a Rapid Access Ice Drill (RAID) currently in development for the US Antarctic Program. RAID is being developed by the authors with support from the US National Science Foundation to support the scientific goals outlined above, and after further testing it will be put to use as a research instrument in Antarctica with broader community participation.

\section{SCIENTIFIC GOALS}

RAID is intended as an ice and rock drilling system that can give the scientific community access to a rich record of geological and glaciological change on a variety of timescales, from the billion-year rock record to thousand-year ice and climate histories recorded at the interface between the ice sheets and underlying solid earth. The RAID drilling platform is mobile, fast and capable of coring both deep ice and bedrock, providing unprecedented access to critical parts of the coupled cryosphere and solid earth. RAID therefore represents a significant technological step forward for glaciological, paleoclimate and geological research. This new drilling platform also supports the vision of future Antarctic research (Zapol and others, 2011) by deploying new sensors, creating remote observing networks, enhancing interdisciplinary research and providing data and samples that can constrain earth system models.

Basic scientific goals used to define the capabilities of RAID were developed at a workshop in Herndon, Virginia, sponsored by the Ice Drilling Program Office in 2011 (Goodge and others, 2011). Refined by further technical and logistical considerations, six resulting goals for the drilling system are listed in Box 1.
Box 1. RAID science requirements.

(1) Provide borehole access to $2500-3300 \mathrm{~m}$ depth in a short timeframe

(2) Drill in dry, frozen-bed conditions in order to avoid contaminating the subglacial hydrologic environment

(3) Retrieve short ice cores $(\sim 50 \mathrm{~cm})$ at depth (reconnaissance for old ice)

(4) Sample the bed interface and retrieve a minimum of $25 \mathrm{~m}$ of bedrock cores (up to $5 \mathrm{~cm}$ diameter)

(5) Traverse over ice and be self-sufficient, alleviating need for fixed camps

(6) Provide a clean borehole that remains open for optical ice-logging, heat-flow measurements and other down-hole observation.

These six core science requirements have carried through every stage of RAID development, informing concept, design, engineering and our planned future operations.

A key to RAID is its ability to make deep boreholes in Antarctica, providing access for logging, core sampling and placement of borehole instrumentation. More importantly, by virtue of high-speed ice cutting, this drilling system will be able to make multiple boreholes per field season. Together then, the mobility, rapid drilling rates, and deep penetration will allow RAID to make numerous penetrations to the base of the Antarctic ice sheets and thereby establish a borehole array, or observatory. In addition to rapidly making boreholes, this drilling system will be used to sample ice, glacial bed materials and bedrock using a rotary diamond coring assembly inserted by wire line. RAID thus provides both deep borehole access and the ability to core solid materials. Future development of equipment for clean access will also allow RAID to explore areas where ice is melted or for penetration into subglacial lakes.

In addition to its interdisciplinary focus, RAID is also designed to be autonomous, lightweight and environmentally benign. These design parameters for RAID reflect a need to economize and add efficiency to activities within the US Antarctic Program, as highlighted by Augustine and others (2012). Borrowing the catchphrase 'lean, mean, and green,' a central theme throughout the RAID design process has been to build in operational autonomy, independence from airlift support, compact and lightweight traverse capability, nimble and swift operation, energy efficiency, drilling fluid conservation, low environmental impact, minimal staffing and minimal footprint of scientists in the field. As detailed below, the RAID system is containerized and towable by tractors in a mobile format, thus being capable of visiting several sites per season without establishing fixed camps. We currently estimate a complete drilling cycle, from site preparation through setup, drilling and coring to break-down and mobilization, of $<200$ hours. This will also be achieved by minimizing personnel; ideally 
comprising 2-3 three-person drilling crews for 24-hour operations plus additional traverse staff. Scientific personnel are not expected to travel with the drilling system, in order to reduce field support requirements in favor of efficiency; traverse routes and drilling targets will be pre-selected by integration of surface imagery and subglacial geophysics (radar, acoustics, magnetics, gravity, etc.). Initial core characterization will be done off-site, whereas borehole logging will be done on-site both immediately after drilling and in followon expeditions to capped boreholes.

Figure 1 shows the anticipated area of operations for the RAID drilling system. RAID's initial focus will be in East Antarctica, in consideration of the scientific questions outlined above. RAID will be wintered and staged from the US research station at South Pole, and it will launch from there each season on traverse with sufficient supplies of consumables to drill 5-6 boreholes per season.

\section{ENGINEERING REQUIREMENTS}

Based on the general science goals outlined above, a series of more specific technical requirements was defined in consultation with the Ice Drilling Design and Operations (IDDO) office in Madison, Wisconsin and other consulting engineers. The resulting technical requirements adopted for RAID are listed in Box 2. Specific considerations were given to achieve a balance of mobility, fast drilling rates, minimizing borehole volume, limitation with frozen conditions, efficiency of coring, minimizing drilling crews, energy efficiency, environmental stewardship, ability to withstand the severe Antarctic environment and providing for post-drilling access in a clean, stable, vertical borehole. Despite this large set of competing parameters, the resulting RAID design, described below, achieves an optimized balance of speed, efficiency and minimal environmental impact.

To meet these engineering requirements for both icecutting and coring, several types of drilling systems were considered, including hot-water drills, coiled tube drills, tethered electromechanical drills and jointed-pipe rotary drills. Advantages and disadvantages of each approach are summarized in Table 1. Based on considerations of capability, cutting rate, robustness, ease of use, ability to repair in the field, energy efficiency, length of core and cost, we adopted a conventional mineral industry-type rotary drilling system using jointed hollow drill pipe for fluid circulation and wireline coring, as described in the section below.

\section{RAID DESIGN}

The design for RAID was developed jointly by the authors with an engineering team led by Chris Delahunty of DOSECC Exploration Services (DES) in Salt Lake City, Utah. Members of the design team also included Gary Clow (US Geological Survey), Arnold Law (Machine Engineering, LLC), and Chad Clarke, Dan McClellan, Dennis Nielson and Philippe Wyffels (all of DES).

Principal design specifications of the drilling equipment and parameters of operation are listed in Table 2 .

\subsection{General outline of components}

As shown in Figure 2, the RAID drilling system is designed to penetrate three sections of the ice sheet - porous firn, nonporous glacial ice and a basal section consisting of deep

a

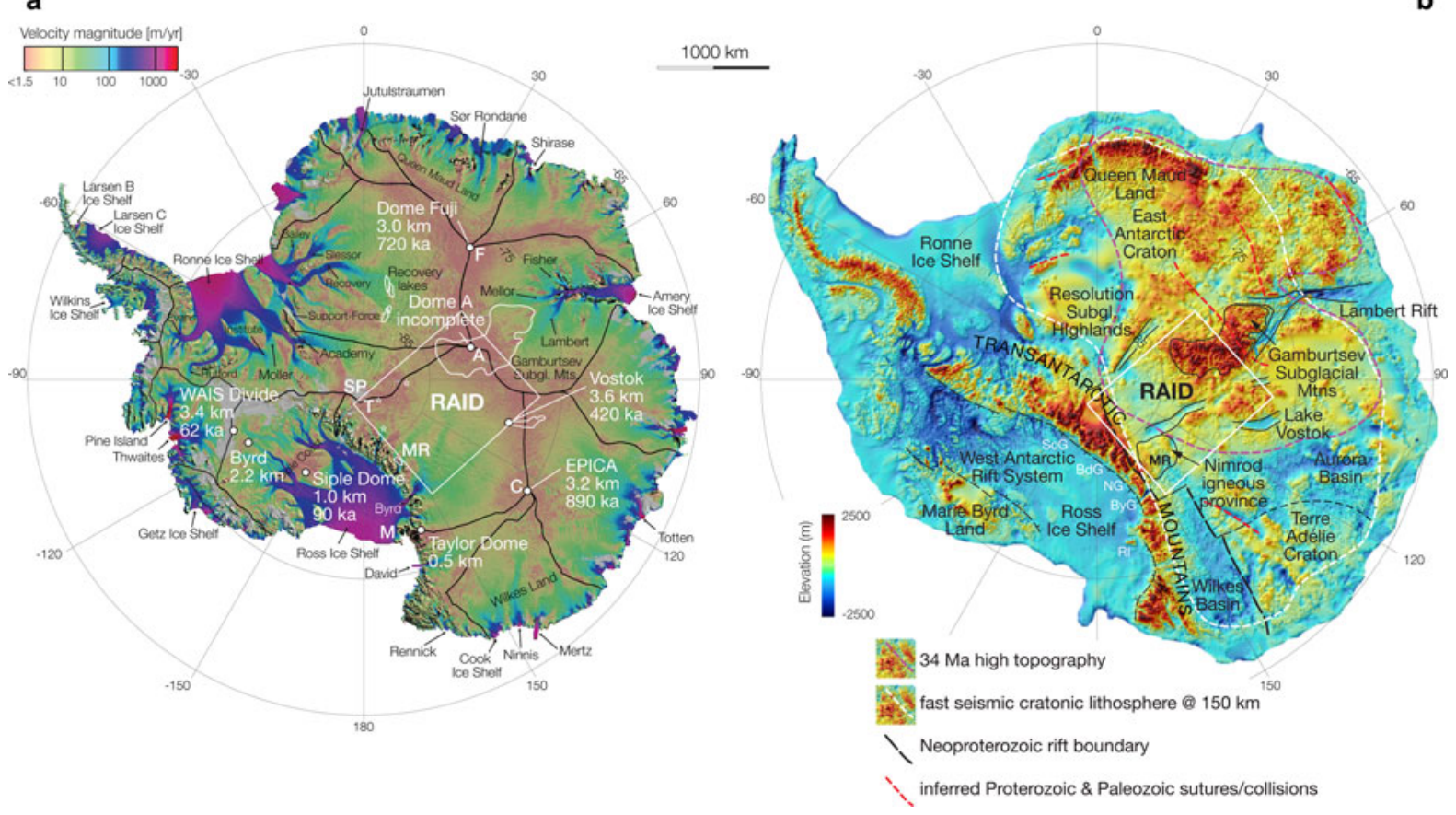

Fig. 1. Maps of Antarctica showing (a) ice velocity derived from satellite interferometry (from Rignot and others, 2011) and (b) sub-ice surface elevations (from BEDMAP2; Fretwell and others, 2013). In (a), black lines show major ice divides; white circles show existing ice cores, with depth of penetration and age of ice record; white outlines show major subglacial lakes. In (b), area of high seismic velocity anomalies at 150 $\mathrm{km}$ depth attributed to fast cratonic lithosphere (dashed white line) from Ritzwoller and others (2001). Area of high topography in East Antarctica (magenta dashed line) from Wilson and others (2011). Nimrod igneous province, Terre Adélie craton and Neoproterozoic rift margin from Goodge and Finn (2010). White box labeled RAID shows area initially targeted for rapid-access drilling. A, Dome A; C, Dome C; F, Dome Fuji; M, McMurdo Station; MR, Miller Range; RI, Ross Island; SP, South Pole; T, Titan Dome. Glaciers: BdG, Beardmore; ByG, Byrd; NG, Nimrod; ScG, Scott. 
Box 2. RAID technical requirements.

(1) Produce $2500-3300 \mathrm{~m}$ borehole to base of ice quickly ( $\leq \mathbf{2 0 0}$ hours)

(2) Minimize borehole diameter $(<\mathbf{1 0} \mathrm{cm})$ to minimize fluid volumes

(3) Drilling only in dry, frozen-bed conditions (no 'clean access')

(4) Retrieve short ice cores $(\sim 50 \mathrm{~cm}$ long) at depth (capture old ice)

(5) Sample bed interface and retrieve $\geq 25 \mathrm{~m}$ of bedrock cores $(>3.5 \mathrm{~cm}$ diameter)

(6) Modified diamond-drilling system equipped with drilling-fluid recirculation, ice chipremoval and chip disposal systems

(7) Deployable as traverse-capable, stand-alone system

(8) Minimum staff for around-the-clock drilling operations (two 3-person crews, $<8$ ?)

(9) Clean borehole to remain open for icelogging for up to 5 a with pressurecompensating fluid

(10) Drilling fluid will be non-freezing; non-icereactive ('hydrophobic'); density similar to water ice $\left(0.92-0.93 \mathrm{~g} \mathrm{~cm}^{-3}\right)$; transparent, with refractive index similar to that of water ice (e.g. ESTISOL 140)

(11) All components capable of operation at high elevation (up to $4000 \mathrm{~m}$ AMSL) and cold air temperature (down to $-40^{\circ} \mathrm{C}$ )

(12) Borehole will deviate $\leq \mathbf{1 0}^{\circ}$ from vertical

ice, glacial bed materials (e.g., till) and bedrock below. The corresponding drilling sections are divided into stages for installation of firn casing, cutting an ice borehole and coring of all solid materials near the base of the ice sheet. In order to drill each of these three sections in sequence, the principal design elements of the RAID drilling system include: (1) a diamond drilling rig, modified to fit inside a traversable module; (2) a pipe rack, for storage and delivery of auger flights, casing pipe and drill rods to the rig; (3) diesel power generators; (4) a mechanical shop and inventory module; (5) a custom-designed fluid recirculation system; (6) metalpipe casing and an inflatable packer unit to make a fluidtight connection through porous firn between the drill rig and impermeable glacial ice below; and (7) a wireline-deployable bottom-hole diamond drilling and coring assembly capable of retrieving ice, sediment and rock cores. These functions are housed in five modularized and sled-equipped ISO-shipping container-type units.

The main drilling components at the surface consist of a modified rotary drilling rig operating in flooded reverse circulation for removal of cuttings and a fluid recirculation system custom-designed to separate ice-cuttings from the drilling fluid and recycle the fluid into the borehole in order to use
Table 1. Summary of various methods employed for deep-ice drilling

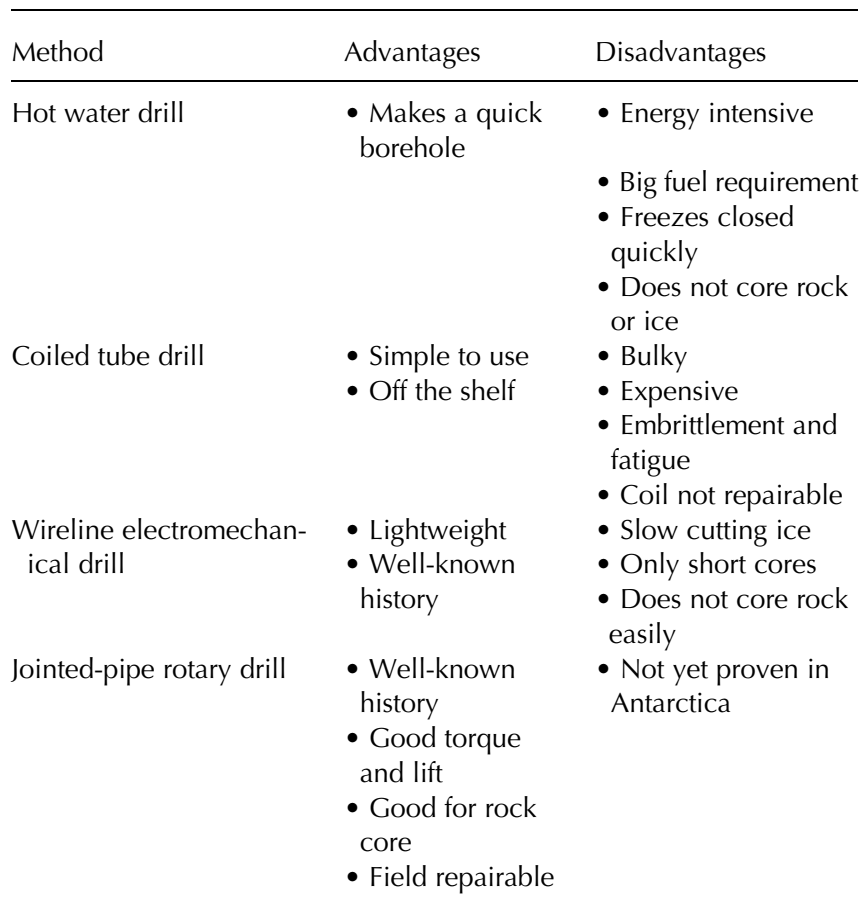

it efficiently and minimize supply. The upper firn section will be cut by the drilling rig using 7.5 inch $(19 \mathrm{~cm})$-diameter ice augers and then cased with 4.5 inch $(11.4 \mathrm{~cm})$ outer diameter (O.D.) steel or composite casing pipe. Casing pipe will be sealed at the bottom against non-porous glacial ice by use of an inflatable rubber packer in the shape of a torus, through which drill pipe can be inserted. A packer enables fluid overpressure in the borehole to be maintained without leaks into the porous firn, and resists both upward and downward forces imparted to the casing by fluid pressure or movement of the drill string. This fluid overpressure in the annulus is crucial during deep drilling to compensate for viscous pressure losses during fluid circulation, in order to prevent warm ice from closing in on the drill pipe in the deepest part of the hole. The RAID packer is an industry-standard 7 inch $(17.8 \mathrm{~cm})$ O.D. model rated to $600 \mathrm{psi}\left(4.1 \times 10^{6} \mathrm{~Pa}\right)$ of inflation pressure and can be inflated by any fluid. Tests in ice indicate that air is the best medium for inflating the packer to a desired pressure of $400 \mathrm{psi}\left(2.8 \times 10^{6} \mathrm{~Pa}\right)$ in order to prevent leakage and slippage. A deep 3.5 inch $(8.9 \mathrm{~cm})$-diameter borehole will then be cut in the ice by rotating NRQ size drill rods (2.75 inches, or $7.0 \mathrm{~cm}$, O.D., in $10 \mathrm{~m}$ rod lengths) equipped with tungsten-carbide or hardened-steel bits. A diverter bolted to the top of the casing with a gasket flange has an inlet that allows the drilling fluid to be pumped downward within the annulus between the casing and the drill rods (reverse circulation), then down the annulus between the ice borehole wall and drill rods, and finally to pass across the bit face in order to flush ice cuttings up through the center of the drill rods. Drilling fluid will be circulated by pumps on the drilling rig and pass through a series of mechanical, gravity and melting-coalescing stages to separate ice from drilling fluid before it is recycled into the borehole. RAID will use ESTISOL 140 as the drilling fluid (see below). 
Table 2. Summary of RAID design specifications and operating parameters.*

\begin{tabular}{|c|c|c|c|}
\hline & Value & Units & Notes \\
\hline \multicolumn{4}{|l|}{ Technical specifications } \\
\hline \multicolumn{4}{|l|}{ Module weights } \\
\hline Drill module & $58000(26300)$ & lbs (kg) & Fabricated flat rack \\
\hline Rod module & $48000(21800)$ & lbs $(\mathrm{kg})$ & Fabricated flat rack \\
\hline Power module & $40000(18100)$ & lbs (kg) & Modified ISO container \\
\hline Fluid recirculation module & $36000(16300)$ & lbs (kg) & Modified ISO container \\
\hline Shop module & $36000(16300)$ & lbs (kg) & Modified ISO container \\
\hline Boart Longyear rotary drilling rig & & & LF230† \\
\hline Generator capacity (2) & 500 & $\mathrm{~kW}$ & Caterpillar C18 \\
\hline Electric prime mover capacity & 300 & Hp & Baldor \\
\hline Fluid pump maximum capacity & $36(134)$ & gpm (lpm) & FMC Bean pump \\
\hline Drilling fluid & & & ESTISOL 140 \\
\hline Air compressor capacity & $250(7080)$ & cfm (lpm) & Ingersoll Rand \\
\hline Air lift tubing (O.D.) & $0.75(1.9)$ & in $(\mathrm{cm})$ & Aluminum rod with check valve \\
\hline Drill rod length & $30(9)$ & $\mathrm{ft}(\mathrm{m})$ & Heat-treated steel alloy, NRQ thread \\
\hline Drill $\operatorname{rod}(\mathrm{O} . \mathrm{D}),. \mathrm{NRQ}$ & $2.75(7.0)$ & in $(\mathrm{cm})$ & \\
\hline Drill rod (I.D.), NRQ & $2.4(6.0)$ & in $(\mathrm{cm})$ & \\
\hline Ice auger (O.D.) & $7.5(19.1)$ & in $(\mathrm{cm})$ & \\
\hline Firn casing (O.D.), HWT & $4.5(11.4)$ & in $(\mathrm{cm})$ & Steel alloy \\
\hline Borehole packer (O.D.) & $7(17.8)$ & in $(\mathrm{cm})$ & \\
\hline Ice-cutting outer bits (O.D.) & $3.5(8.9)$ & in $(\mathrm{cm})$ & Tungsten carbide blades \\
\hline Ice-cutting outer bits (I.D.) & $2.2(5.6)$ & in $(\mathrm{cm})$ & \\
\hline Ice-cutting face-centered bits (O.D.) & $2.2(5.6)$ & in $(\mathrm{cm})$ & Tungsten carbide blades \\
\hline Reaming shells (O.D.) & $3.5(8.9)$ & in $(\mathrm{cm})$ & Diamond impregnated steel alloy \\
\hline Bottom-hole assembly (O.D.) & $3.5(8.9)$ & in $(\mathrm{cm})$ & steel alloy \\
\hline Bottom-hole assembly (I.D.) & $2.2(5.6)$ & in $(\mathrm{cm})$ & \\
\hline Diamond coring bit (O.D.) & $2.2(5.6)$ & in $(\mathrm{cm})$ & Impregnated diamond cutters \\
\hline Diamond coring bit (I.D.) & $1.5(3.8)$ & in $(\mathrm{cm})$ & \\
\hline Core barrel (O.D.) & $2.2(5.6)$ & in $(\mathrm{cm})$ & \\
\hline Core barrel length & $10(3)$ & $\mathrm{ft}(\mathrm{m})$ & \\
\hline \multicolumn{4}{|l|}{ Operating conditions } \\
\hline Borehole diameter & $3.5(8.9)$ & in $(\mathrm{cm})$ & \\
\hline Maximum borehole depth & 3300 & $\mathrm{~m}$ & \\
\hline Drill rotation rate & $400-500$ & $\mathrm{rpm}$ & \\
\hline Fluid circulation rate & $25(95)$ & gpm (lpm) & \\
\hline Penetration rate & $2.5-3.0$ & $m \min ^{-1}$ & \\
\hline Rod cycle rate & $\sim 5$ & $\min$ & \\
\hline Fluid volume (per $3300 \mathrm{~m}$ hole) & $5400(20400)$ & gal (liters) & \\
\hline Crew size (to operate) & 3 & & \\
\hline
\end{tabular}

* HWT, standard flush-joint casing size (4.0 in I.D., 4.5 in O.D.); I.D., inner diameter; ISO, International Standards Organization; NRQ, standard diamond drill pipe size (2.38 in I.D., 2.75 in O.D); O.D., outer diameter.

+ See Boart Longyear LF230 data sheets.

Ice, bed and bedrock cores (1.5-1.9 inch, or 3.8-4.8 cm, diameter) will be retrieved into core barrels using a wireline-deployable bottom-hole assembly (BHA) equipped with thin-kerf diamond rotary bits. This BHA fits within the drill rods and so can be deployed without pulling the drill string prior to coring. The entire operation of cutting a borehole and retrieving core will be completed with only one trip of the main drill string to depths of 2500-3300 m, significantly minimizing total time at each drill site. To the extent possible, the RAID drilling system uses off-the-shelf, industrystandard components; in many cases, however, individual components were custom designed or sized for appropriate application in the RAID system. Key components of the RAID system are detailed below.

Field deployment of the RAID drilling system in Antarctica is shown schematically in Figure 3. The system consists of five main drilling modules, all containerized and towable over the ice cap, plus supporting equipment and berthing for a minimum complement of drilling staff and all the consumables required for traversing and drilling up to six sites per field season. RAID is designed to be logistically autonomous.

\subsection{Drilling rig and drill-rod modules}

The centerpiece of the RAID design is the drilling rig itself. After consideration of commercially available rigs, we identified the Boart Longyear model LF230 as the best choice for the RAID system. Manufacturer specifications for this coring drill are available at http://www.boartlongyear.com/drillingequipment/surface-coring/lf230/. This rig has multiple advantages: (1) appropriate power, torque and lift capacity (22.7 ton pullback, or $20593 \mathrm{~kg}$ ); (2) adaptable for normal and reverse circulation drilling; (3) up to $9 \mathrm{~m}$ rod pull; (4) simple, hydraulic chuck drive; (5) uses industry-standard drill pipe, bits, and casing; (6) suitable for wireline coring; (7) compact design and skid-mountable; (8) manual leveling capability; (9) convertible to an electric-over-hydraulic prime mover; (10) operable by a 3-person drilling crew; (11) factory engineered to operate at $-40^{\circ} \mathrm{C}$; and (12) readily available 


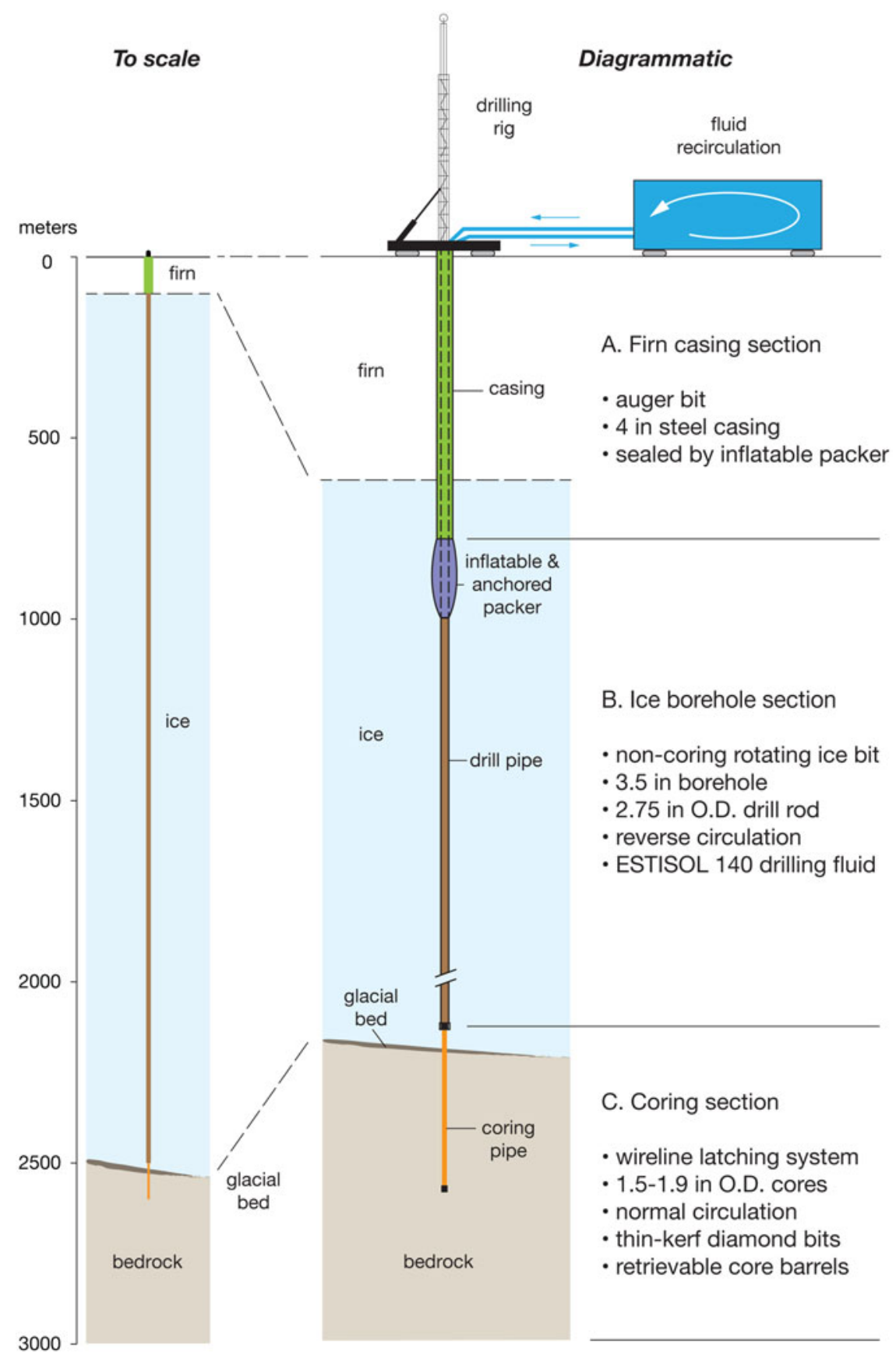

Fig. 2. Schematic diagram showing the main elements of the RAID design using a conventional rotary drilling rig operating in flooded reverse circulation mode in jointed hollow drill pipe. The RAID system involves three stages of drilling and coring, divided here into casing, borehole and coring sections $(\mathrm{a}-\mathrm{c})$. Firn casing is capped at the surface and sealed in non-porous ice by an inflatable packer in order to maintain borehole fluid pressure. The ice borehole will be made with hardened ice-cutting bits in a reverse fluid circulation mode in order to evacuate cuttings. Coring will be done with a wire line BHA using thin-kerf diamond drill bits in a normal fluid circulation format.

on the commercial market. The RAID drilling rig has been modified with a $300 \mathrm{HP}$ electric motor running hydraulics in place of a diesel engine, along with soft-start capability provided by an AC solid-state motor control, which decreases the weight of the system, provides greater energy efficiency, and provides for greater ease of use in the Antarctic environment.

The drilling rig and drill-rod rack modules were custombuilt from cold-rated C-channel steel, bolted to form two $45 \mathrm{ft}(13.7 \mathrm{~m})$ and $40 \mathrm{ft}(12.2 \mathrm{~m})$, respectively, 'flat racks' that are mountable on sleds and equipped with retractable vinyl-coated woven fabric side and top curtains for access during drilling operations. The drill-rod rack is equipped with an auger trolley that allows the drill crew to move hollow-stem auger sections to the front of the pipe rack skid with little effort. The drill rig and drill-rod modules are outfitted with hydraulic leveling legs and will be supported by rig mats in the field to reduce ground pressure. When deployed, the drilling rig and drill-rod modules will be joined by a fixed platform and the drilling crew work area will be covered by a woven fabric canopy for environmental protection (Fig. 4). The canopy is light enough that the hydraulic rams of the drill mast can lift it into place, but durable enough to resist snagging and wind; it is designed to withstand wind loads of $80 \mathrm{mph}$ $\left(36 \mathrm{~m} \mathrm{~s}^{-1}\right)$. 


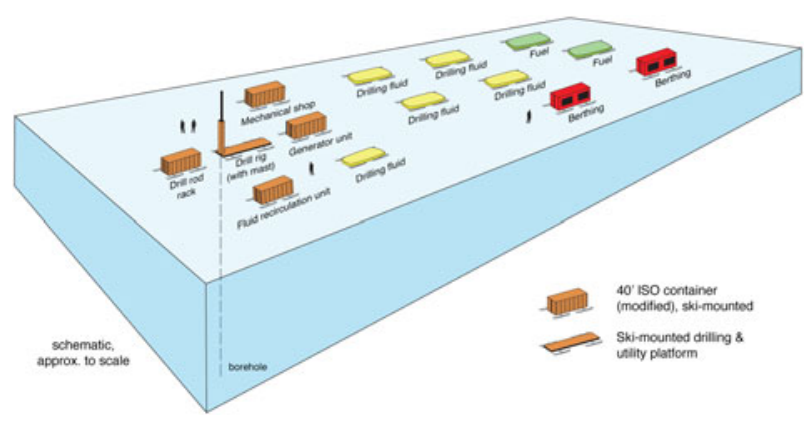

Fig. 3. Field layout for RAID (schematic and approximately to scale), including five main drilling modules (brown). Tower shows location of drill rig platform. Not shown are hoses and wiring to connect drilling components, fuel bladders, camp facilities, tractors and other equipment. Drill pipe rack can hold up to $3500 \mathrm{~m}$ of drill rod, depending on rod diameter. Drilling fluid and fuel will be supplied in flexible bladders.

\subsection{Fluid recirculation system}

A custom-designed fluid recirculation system was designed for RAID to move fluid and ice cuttings between the surface fluid supply reservoirs, the wellhead and the borehole (Fig. 5). It is a closed-loop system capable of both normal and reverse circulation. The fluid recirculation system itself houses all of the equipment needed to prime the borehole with fresh drilling fluid, separate ice cuttings from the drilling fluid and filter the fluid for recycling into the borehole (Fig. 6). We modified a standard $40 \mathrm{ft}(12.2 \mathrm{~m})$ $\mathrm{Hi}-\mathrm{Cube}$ ISO container by dividing it into cold and warm rooms to accommodate a two-stage separation process. The cold room, designed to remain at ambient conditions, contains fluid storage and supply tanks, pumps, filters and a screen-shaker unit used to separate ice chips and recover drilling fluid. The larger warm room contains tanks for melting ice cuttings, coalescing drilling fluid, collecting waste water and returning filtered fluid to the cold-room supply. The warm room also houses pumps and filters; a large-capacity compressor used for maintenance as well as delivering air to the borehole during air lift operations; a boiler unit for warming the melting tank; a programmable logic control interface to monitor temperatures, fluid levels and pressures; an electrical cabinet and motor control center and space heater. During drilling operations, fluid is provided to the supply tanks in the cold room from an external supply in flexible bladders and then pumped into the borehole (blue fluid paths in Fig. 6). Fluid returning from the borehole contains ice cuttings and is introduced across the screen-shaker in the cold room, which mechanically separates fluid from ice on two sloping screens of coarse and fine mesh size, vibrating by an eccentric cam. Shop and field tests of the shaker indicate that we can achieve $\sim 90 \%$ recovery of pure fluid from this step alone. Fluid passes through the screens and into a return tank below. Mostly-dry ice cuttings then fall off the shaker screens, set across a pass-through into the warm room and into the melting tank.

A closed-loop warm fluid line from the boiler, coupled with waste heat captured from the power generators, provides energy to melt the remaining ice (red fluid paths in Fig. 6). Because ESTISOL is an oil-based, water-insoluble fluid that floats on liquid water, the two-phase fluid is pumped to a coalescer tank where ESTISOL is skimmed off the water and captured in a fluid return tank below. Waste water from melting of ice is virtually free of drilling fluid and periodically purged to the outside. The two-stage process of separating ice and drilling fluid, combining

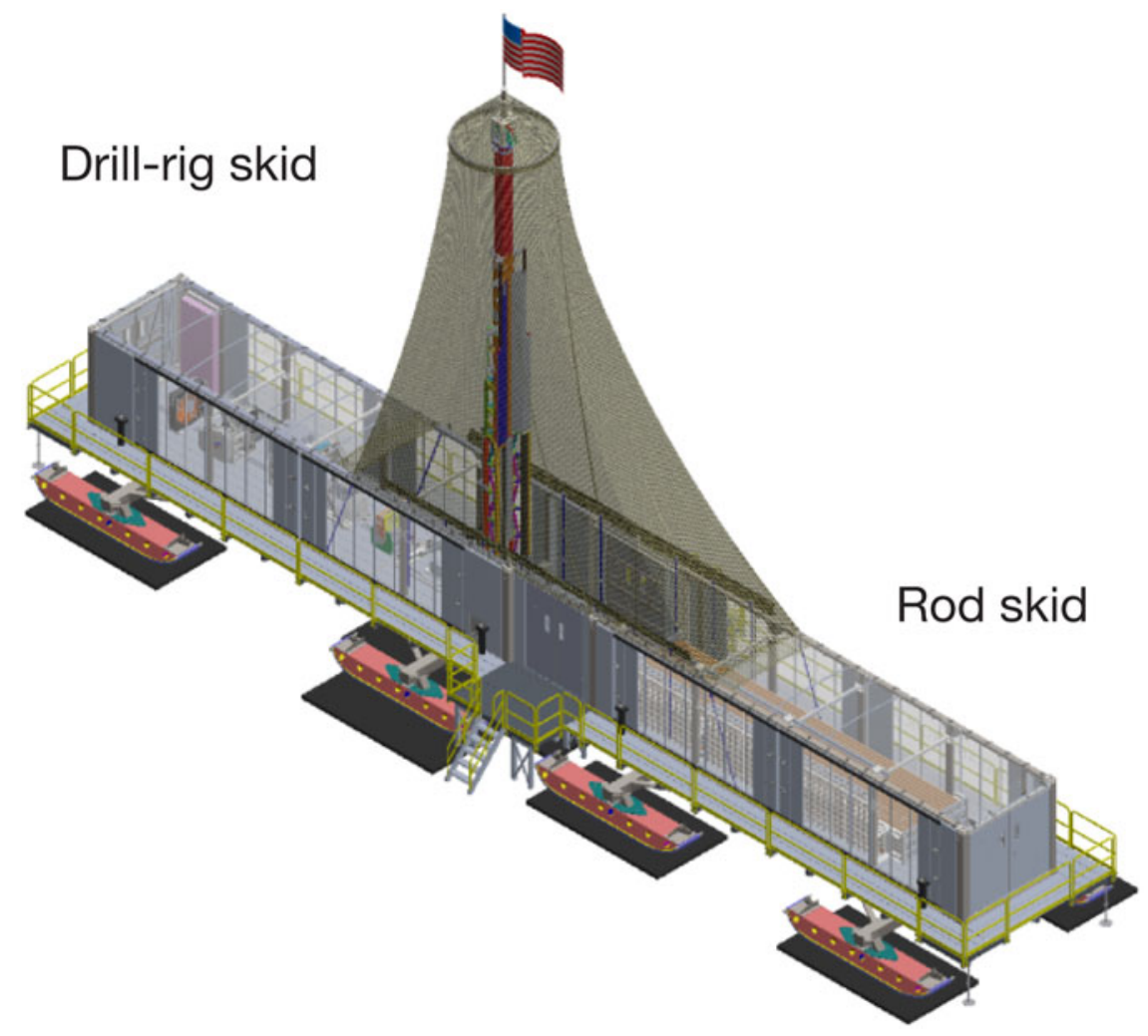

Fig. 4. Field deployment of drill and rod modules on sleds. Drill rig (background) and drill-rod racks are joined by a work platform and covered by a canopy of reinforced fabric. 


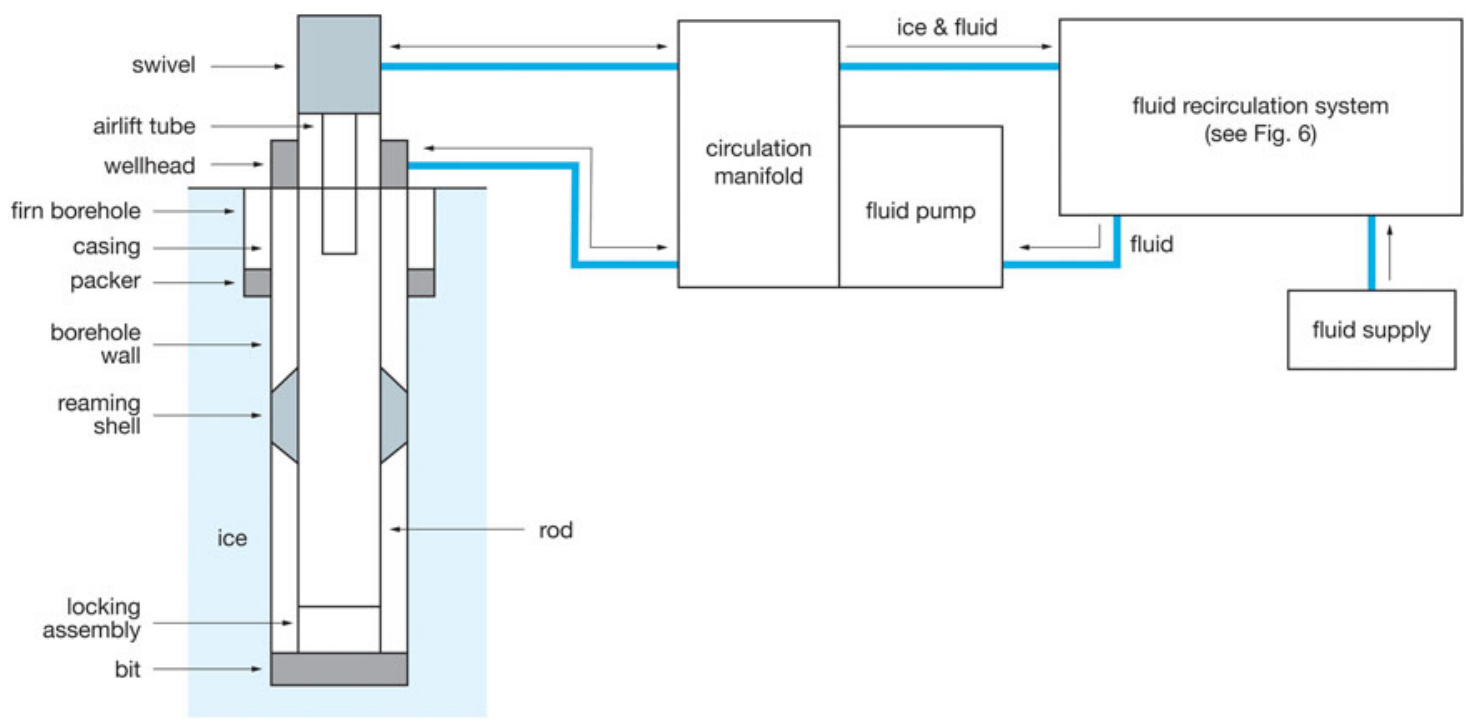

Fig. 5. Generalized schematic diagram illustrating the closed-loop fluid recirculation system that connects the surface fluid reservoirs with the wellhead and borehole. Details of the fluid-processing module are shown in Figure 6 .

mechanical and melting-coalescing steps, is highly effective and capable of keeping up with the maximum drilling rates achieved by the LF230 drill.

\subsection{Other modules}

Other modules include the drill-rod rack skid, built in the same configuration as the drilling rig skid, and power and shop modules each fitted-out in $40 \mathrm{ft}(12.2 \mathrm{~m})$ ISO containers. The drill-rod skid includes space for all the necessary drill rods, augers and casing pipe to drill through $150 \mathrm{~m}$ of firn and $3300 \mathrm{~m}$ of ice. It includes a hoist and trolley system for moving and lifting drilling components. Power is provided to the RAID equipment from a central generator module containing twin Caterpillar C- 18500 kW diesel generators. The generators are redundant and typically only one is required for all drilling and support operations. Power is distributed to the other modules through an elevated cable system that is assembled at each drilling site. A ventilation system allows for control of temperature within the generator module in both automatic and manual modes. The shop module is configured with ample storage for drill bits, bottom-hole tooling, spare parts, and consumables and a basic workbench with machine tools and welding equipment for field repairs. All five RAID modules are outfitted for firesuppression, consisting of an ABC dry chemical system operable in both automatic and manual modes. Fire detection is possible by thermal sensors, linear detection wire, infrared, push-button and remote controls, and the system is connected to a main fire control panel at the drill station operation interface.

\subsection{Tooling}

The combined drilling and coring requirements of the RAID system while operating at depths up to $3300 \mathrm{~m}$ and cutting through different materials mandated a unique solution. RAID uses a BHA consisting of an outer ice-cutting bit and tubes that remain in the borehole at all times with the drill rods (Fig. 7a). The BHA attaches to the outer bit and is in line with the drill rods; it is the chambering device for both the non-coring assembly used in ice cutting and the inner coring assembly. Either a face-centered ice-cutting bit or coring tools are inserted in and removed from the BHA by wireline. This allows us to change from drilling to coring without pulling the entire drill string. From bottom to top,

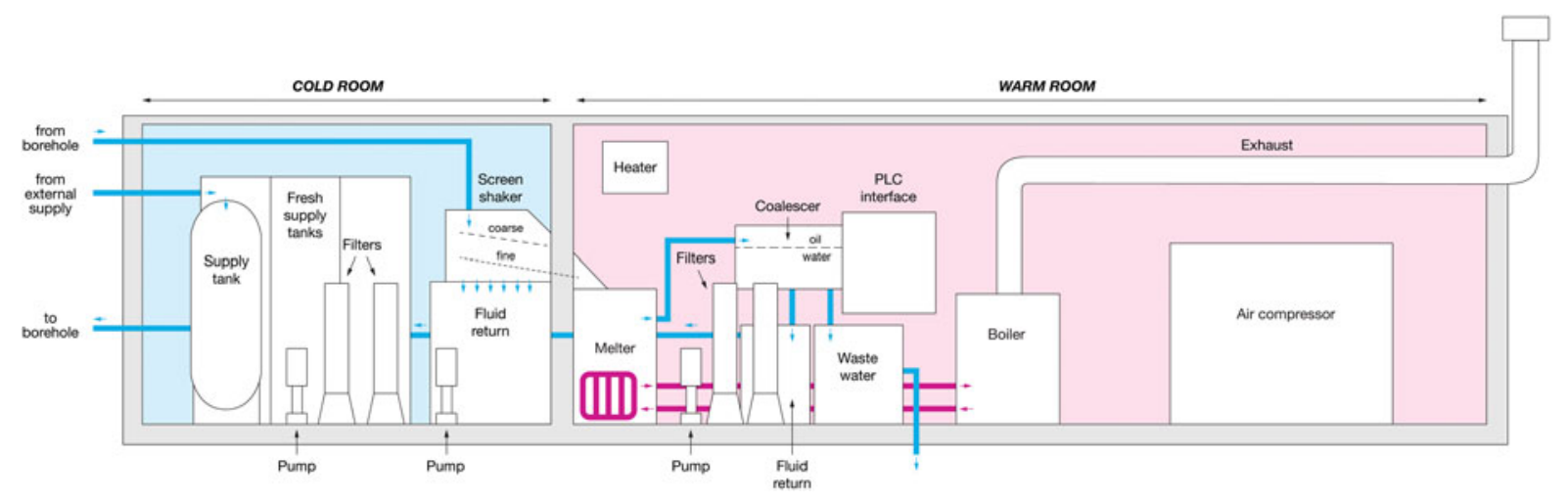

Fig. 6. Simplified schematic diagram of fluid recirculation system (FRS) shown to scale as built out in a $40 \times 9.5 \mathrm{ft}(12.2 \times 2.9 \mathrm{~m}) \mathrm{Hi}-\mathrm{Cube} \mathrm{ISO}$ container. FRS is divided by a partition wall into unheated and heated spaces (cold and warm rooms, respectively). Blue lines show general path of drilling fluid; magenta lines show warm fluid circulation loop. Not shown: electrical panels, power distribution, fire suppression, lighting, gauges and readouts and other minor components. 
a

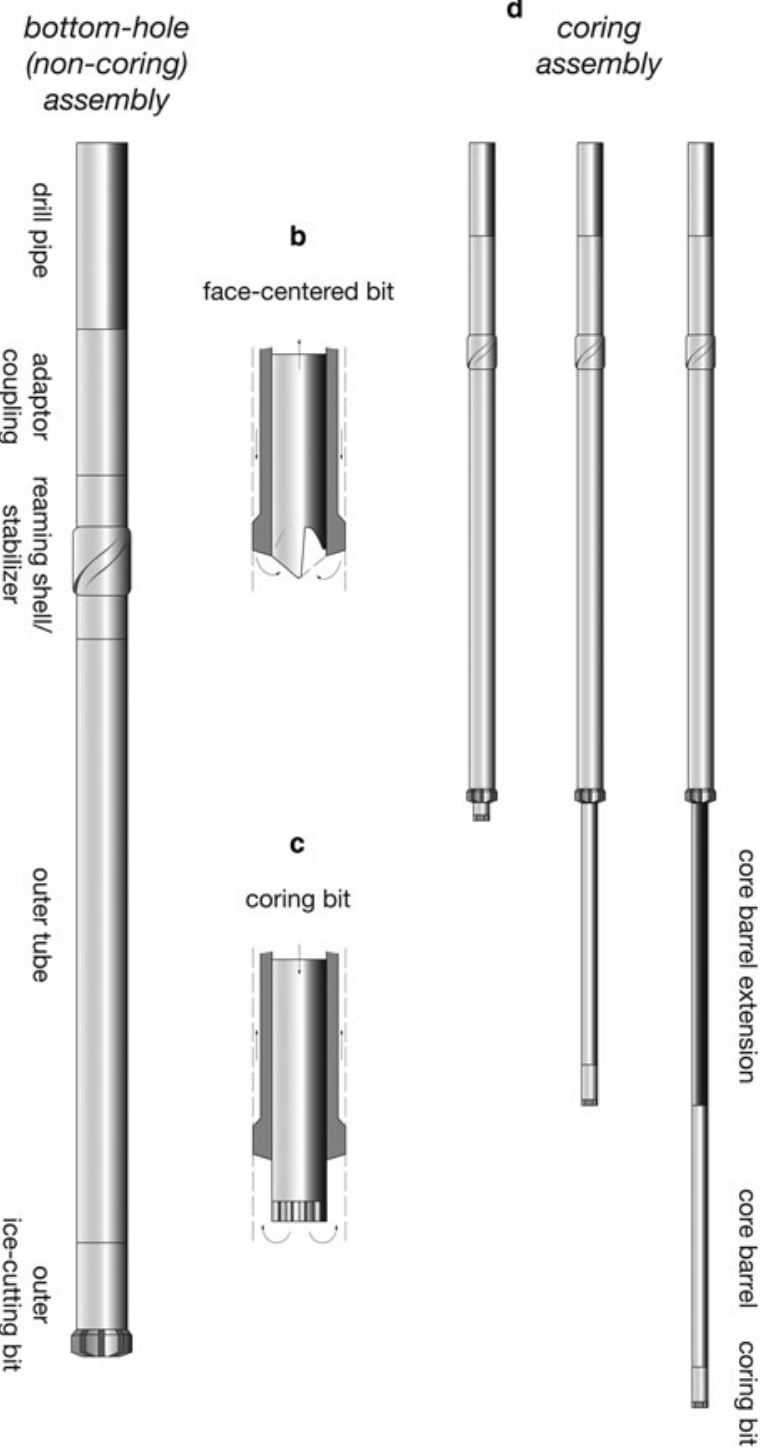

Fig. 7. Schematic diagrams showing bottom-hole tools, including: (a) non-coring bottom-hole assembly $(\mathrm{BHA})$, with reaming shell and outer ice-cutting bit; (b) face-centered bit for cutting ice, latched into position within the BHA; (c) diamond coring bit, substituted by removing the inner ice-cutting bit and latching in on wire line; and (d) a sequence of coring steps showing progressive advance of the coring bit and core barrel with extensions as needed. Core barrels are available in 1.5 and $3 \mathrm{~m}$ lengths. Not to actual scale. Not shown are inner landing ring, latching mechanisms for vertical and rotational locking and pulling tools.

the BHA consists of the outer bit, landing ring, outer core barrel, rotational driver coupling, vertical locking coupling, reaming shell and adapter coupling. The locking coupling hosts the latch head that attaches to the inner core barrel. Separate reaming shells can be used to help centralize the drill string and condition the borehole.

The RAID system has three primary drill bits used in the ice drilling and coring sections of the hole. The outer bit, which is the primary cutting mechanism through the ice, has a 3.5 inch $(8.9 \mathrm{~cm})$ O.D. If required, the bit diameter can be increased and will not adversely affect drilling of the hole; however, doing so will increase the drilling fluid requirements. The outer bit is $\sim 20 \mathrm{~cm}$ long and houses the landing ring, a hardened piece of steel designed to stop

downward momentum of the inner tools when the landing shoulder contacts the landing ring. Ice-cutting outer bits are available in both hardened steel and tungsten carbide formats. We have also designed bits with cutters of different materials such as high-speed steel, carbide and diamond that will allow us to drill through ice and expose diamond cutters if contact is made with hard materials such as an entrained glacial boulder or compacted till. The second-stage noncoring assembly is a wire-line retrievable inner barrel with a second face-centered bit (Fig. 7b). It consists of the inner ice-cutting bit, landing shoulder, spacer tube and latch head. This tool is used for drilling operations without taking core samples. It is the crux of the RAID concept and is designed to penetrate the ice sheet as quickly as possible, allowing cuttings and drill fluid to pass through its inner diameter. This tool, along with the design of the outer barrel, allows a drill crew to drill ahead to a designated depth and then, with the wire line, retrieve the non-coring assembly in order to sample ice, transition of the ice/bedrock, bedrock and afterwards redeploy the non-coring assembly if needed. A third bit is used to core ice, glacial bed materials and rock (Fig. 7c). It is patterned after a standard mining industry hard-rock bit, with different configurations to handle ice, till, cobbles and rock. This bit has as thin a kerf as possible in order to allow passage through the $\mathrm{BHA}$ bit and retrieve the largest possible diameter core $(\sim 1.5$ inch, or 3.8 $\mathrm{cm}$, diameter).

RAID uses custom-designed 'running' and 'pulling' tools to deliver and retrieve the inner barrel from the BHA. Designs of the latch head and the running and pulling tools are based on designs used in the oil industry and for marine scientific drilling; they are positive locking devices that prevent the inner barrel from disconnecting. Because the drilling fluid is less viscous than typical water-based muds, the inner barrel cannot be dropped inside the rods and allowed to free fall; these tools are deployed in and out of the drill string via a 3/16 inch $(0.5 \mathrm{~cm})$ swaged wire rope that is spooled by the wire line winch of the LF230 drill rig.

A custom-designed coring assembly will be used to take spot ice cores, drill through the boundary zone and glacial bed, and into bedrock. The coring assembly protrudes from the BHA in 1.5 and $3 \mathrm{~m}$ increments, or multiples thereof. To recover $25 \mathrm{~m}$ of core, the coring assembly first latches into the $\mathrm{BHA}$, advances by rotation of the drill string, collects up to $3 \mathrm{~m}$ of core and then is retrieved by the pulling tool (Fig. 7d); after core is removed from the barrel, additional increments of core will be taken by adding extensions to the core barrel and the tool is run to the bottom to begin another section of coring. Coring rods are designed in $3 \mathrm{~m}$ lengths of B size (2.2 inch, or $5.6 \mathrm{~cm}$, O.D.). Coring continues in this incremental fashion, with the BHA moving up and down within the previously drilled borehole enough to advance the coring assembly, until the desired amount of core is recovered with successive trips of the wire line.

\subsection{Key design innovations}

Since completion of an initial feasibility study undertaken in collaboration with IDDO (Gerasimoff, 2012), which identified a jointed-pipe rotary drill as the most appropriate technology for this application, subsequent design work completed by DES and the RAID scientific team has resulted in the following key design features and innovations: 
(1) Flooded reverse fluid circulation. A key element in the RAID design is use of a flooded reverse-circulation mode of drilling. In reverse circulation, the drilling fluid is pumped downward along the annulus on the outside of the drill pipe and returned along with cuttings upward through the middle of the drilling pipe (Fig. 8). This method was adopted in order to maximize the diameter of ice and rock cores (requiring a larger inner diameter (I.D.) drill rod), while at the same time minimizing the risk of clogging by ice chips in the narrow, outer annulus. The RAID reverse circulation system has been designed to maximize flow to achieve rapid borehole cutting. In field tests conducted in North America, we achieved ice-cutting rates of 2.5$3.0 \mathrm{~m} \mathrm{~min}^{-1}$. During rock coring, however, the drilling system will be returned to normal mode, in which fine rock cuttings are lifted up the outer annulus and a high flow rate provides adequate cooling and lubrication at the cutting surface.

(2) Custom mechanical/coalescing fluid recirculation system. Perhaps the most challenging and innovative part of the RAID design is the fluid recirculation system. Because of the need to carry all of the drilling fluid required for multiple holes while traversing and to minimize the total amount of fluid used in keeping with environmental stewardship, RAID must continuously recirculate drilling fluid, remove ice cuttings and recycle fluid without substantially warming ice in the borehole. We designed a containerized fluid recirculation system consisting of a series of tanks and pumps that is capable of moving fluid through the borehole and separating the fluid-ice mixture in a two-stage process involving both mechanical screening and melting/coalescing stages, as described above (Fig. 6).

(3) Narrow-wall drill rods. To save on weight of the drill string at depths between 2000 and $3300 \mathrm{~m}$, we will employ custom steel drill rods consisting of a narrowwall mid-body section fitted with standard Boart Longyear-type threaded box-and-pin end joints. We considered composite drill rods consisting of an aluminum mid-body fitted to steel end joints because aluminum provides advantages of lighter weight yet greater tensile strength at cold temperatures. However, contrasting thermal expansion of steel and aluminum raised concerns about the viability of the metal joints at low temperatures in Antarctica.

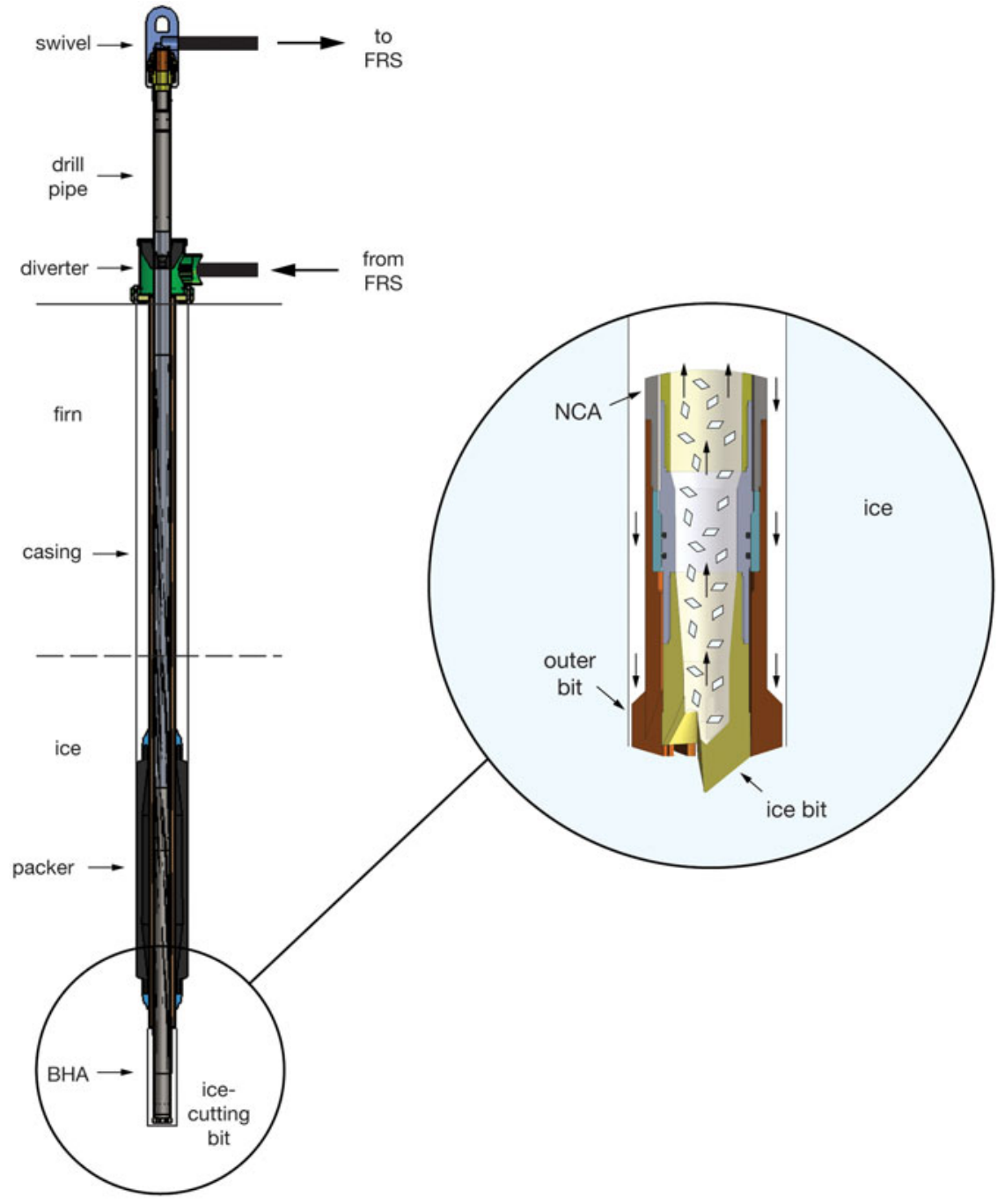

Fig. 8. Schematic diagram showing the upper portion of the drill string from the surface down to non-porous ice. Fluid circulates from the borehole to the fluid recirculation module via the drill-pipe swivel and diverter at the surface. Firn casing is sealed below within nonporous ice by use of an inflatable packer, through which the drill string penetrates. Fast ice cutting is made possible by use of flooded reverse circulation, in which drilling fluid flows downward within the annulus surrounding the drill rods, passes over the cutting face and then carries ice cuttings away up the inside of the drill rods (inset). 
(4) Custom rod rack for inventory and driller operation. A custom-designed rod rack is included with the RAID design. It is built on a bolted steel rack like that used for the drilling rig, and it includes a sliding trolley for auger flights, racks for casing pipe and drill rods, retractable vinyl side curtains and top cover, and a modular catwalk. It is capable of carrying up to $3500 \mathrm{~m}$ of drill rods. This unit, when mounted on skis, will be connected to the drilling rig platform by a modular deck to create a workspace for ease of rod handling to and from the drilling rig (Fig. 4).

(5) Airlift. To enhance the ability of the fluid circulation system to maintain flow and appropriate pressure compensation during making of the deepest parts of the borehole, an air-lift system will be employed. In this standard oil-field and rock drilling practice, compressed air is injected into the inside of the upper $\sim 60-150 \mathrm{~m}$ of the drill pipe to reduce the overall density of the upward-flowing fluid-ice mixture. The resulting increase in its buoyancy augments the driving force for fluid circulation, overcoming frictional pressure losses and thus ensuring a rapid flow rate of the drilling fluid. Use of an air-lift system will also help maintain the desired fluid pressure compensation in the deeper, warmer parts of the borehole, thereby reducing the likelihood of warm, ductile ice 'ballooning' into a cavity in response to fluid overpressure. The air-lift process and fluid pressure compensation are discussed separately below.

(6) Augering of firn. It is necessary to case the upper $\sim 130 \mathrm{~m}$ of the borehole passing through the porous and permeable firn in order to prevent loss of pressurized fluid during drilling. The borehole in firn will be larger diameter $(7.5 \mathrm{in}$, or $19.1 \mathrm{~cm})$ and cased with steel pipe $(4.5 \mathrm{in}$, or $11.4 \mathrm{~cm})$. We have elected to make this larger-diameter hole for the casing with conventional ice augers deployed by the LF230 drill rig because augers are fast, energy efficient, compact, proven in similar settings (e.g., South Pole), and exploit the rig's high torque capability. Other options were considered, such as a hot water drill, impact driver, or a rotary air (RAM) drill, but these were discarded as too costly in terms of fuel consumption, larger compressor requirements, greater pumping/ lifting requirements and possible damage to casing sections. The RAID system will use a light soil auger borrowed from the geotechnical industry, with a 7.5" $(19.1 \mathrm{~cm})$ O.D. bit appropriate for cutting ice. After augering a firn borehole to accommodate casing pipe, and once casing is set and a seal is created in nonporous ice with a packer, the ice-cutting process will begin using the RAID rig with the conventional drill rods.

(7) Inflatable packer. To seal the base of the casing against non-porous ice (at $130 \mathrm{~m}$ depth), we will use an inflatable casing 'packer' with a flexible rubber membrane that is inflated to seal against solid ice. This industrystandard packer has an outside diameter of 7 inches $(17.8 \mathrm{~cm})$ and can be fitted with spikes or studs to ensure good coupling against back-pressure from the borehole fluid. The packer performed as expected in a recent test at the firn-ice transition near McMurdo Station, making a leak-tight seal when inflated with air to a pressure of 350 psig (2.4 MPa).
(8) Wire line bottom-hole assembly. To reach deep levels in the ice and retrieve ice and rock cores on a rapid timeframe, the RAID design consists of a BHA into which ice-cutting and coring tools can be deployed on wire line. After reaching the base of the ice sheet, removal of a detachable inner ice-cutting bit will allow us to insert a wire line coring system that will latch into the outer drill pipe and advance behind a diamond coring bit. Such a wire line system will allow us to take the required cores without tripping drill pipe, saving considerable time while on site. For coring, sections of core barrel and an attached coring bit are lowered into the drill string via a dedicated wire-line winch located in the drill module and mechanically latched to the BHA upon landing (Fig. 7). Positive latching provides both vertical and rotational coupling between the coring tools and the bottom-hole assembly. Once coupled to the drill string, the inner core barrel and coring bit move in synchronous rotation with the drill string, which is rotated by the drilling rig. The coring bit advances by weight-on-bit, while the outer ice-coring bit remains at the same level in the ice borehole. Once a coring section is completed, the inner core barrel is lifted on wire line to the surface, core removed, a core barrel extension is added and the process is repeated.

(9) Environmental canopy. We designed a removable fabric canopy that can be hoisted up the drill mast and guyed out to anchors, making a taut tent-like cover to protect the rig and drilling crew from the Antarctic elements. It is designed for quick rig-up and rig-down ( $<1$ hour), and also to minimize wind loading.

(10) Heat-efficient design. To the extent possible, we have designed the RAID system with heat-exchange capability in order to recover as much waste heat as possible for use elsewhere, and, likewise, for efficient cooling using ambient air temperatures. For example, excess heat from power generation will be used to melt the ice chips during fluid recovery, whereas a heat-pump concept will be applied to chill this fluid before it is re-injected into the borehole.

(11) Containerized subsystems. Each of the main components are designed to fit within standard-dimension ISO containers and/or flat racks of similar dimension. These containers are designed to fit on either skis or inflatable pontoons for over-snow traversing. They will be fitted with leveling, hydraulic, control and heating systems, fluid pumps, catwalks, insulation and retractable side and top curtains. The containerized systems are designed to be strong and weatherproof, yet provide ready access to the drilling crews.

(12) Arctic ratings for components. All critical components will have industry-grade Arctic ratings to reduce the risk of failure in Antarctic conditions. Arctic-rated equipment will include power equipment, motors, fluids, seals, hoses, steel, fire safety equipment and electric wire jacketing.

\subsection{Drilling fluid}

The choice of drilling fluid affects the design in numerous ways, such as compatibility with elastomer seals, the fluid 
viscosity's impact on the permissible width of the annulus and the fluid density's impact on the required fluid level for long-term borehole stabilization. For this reason, we decided to choose a drilling fluid early in the design process. A wide range of fluids was considered, including $n$-butyl acetate, silicone oil, and refined derivatives of kerosene such as ISOPAR-K. Our search was heavily influenced by the experience of the ice-coring community in identifying a replacement for the halocarbon HCFC-141b, which has been phased out by the Montreal Protocol to protect atmospheric ozone. Borrowing on pioneering work by Danish scientists in successful ice-coring operations in Greenland and Antarctica, we decided at an early stage to adopt ESTISOL 140 as the drilling fluid for RAID (Sheldon and others, 2014). This fluid has all of the desired properties listed in the technical requirements above, satisfying the needs for low viscosity at low temperature, drill lubrication, ice-chip flotation, borehole pressure stabilization, optical quality, safety, modest cost and environmental suitability.

\subsection{Air-lift process}

For the air-lift process, $60 \mathrm{~m}$ of $3 / 4$ in $(1.9 \mathrm{~cm})$ diameter aluminum rods are inserted into the drill rods and secured to a swivel designed for air lift using positive-locking quickdisconnects. The air-lift rods are run into the drill string one section at a time and a check valve is used to create neutral buoyancy. During drilling, compressed air is injected into the aluminum rods and adjusted as needed. A check valve at the bottom prevents back-flow of drilling fluid. Maximum airlift capability is achieved at a depth of $\sim 400$ fbs $(121 \mathrm{mbs})$. To add more drill rod, the air-lift rods are detached and then reconnected to resume drilling using the following procedure.

At the end of a drill run $(9 \mathrm{~m})$, flow is stopped and the drill rods are secured in the foot clamp and chuck. The swivel is unthreaded from the drill rods and pulled up to expose the air-lift tube connection, and the neutrally-buoyant air-lift rods are disconnected. The swivel is attached to a new rod from the rod rack and pulled up over the drill head. The air-lift rod is then manually inserted upward into the suspended drill rod until it connects with a coupler at the base of the swivel. Once a positive connection is made, the drill rods above are threaded to the rods in the chuck. Flow of ESTISOL and air is resumed and drilling proceeds.

\subsection{Borehole pressure considerations}

The central concept of RAID is to keep the logistical footprint small and nimble, which translates directly to keeping the borehole diameter as small as possible due to the fact that the volume of drilling fluid required increases as the square of the borehole diameter. For example, a 3.5 inch $(8.9 \mathrm{~cm})$ diameter borehole to a depth of $3300 \mathrm{~m}$ will require 5400 gallons (20 $440 \mathrm{l})$ of fluid, whereas a 7 inch $(17.8 \mathrm{~cm})$ diameter borehole requires $>21000$ gallons (79 500 I) of fluid. However, as the borehole diameter becomes smaller, frictional pressure losses in the moving fluid increase. This pressure loss makes it increasingly difficult to maintain adequate borehole pressure during drilling, which is necessary to prevent the ice from closing in on the drill pipe and stopping fluid circulation. For this reason, we engaged in a lengthy optimization process, iterating between engineers and scientists on the design team, informed by a fluid-mechanical model of borehole pressure and frictional pressure loss (based on the Darcy-Weisbach equation) that we constructed for this purpose.

Briefly, the model is steady state and starts with ice density, ice velocity and temperature profiles computed from a modified Herron and Langway (1980) firn densification model, a Dansgaard and Johnsen (1969) 1-D ice flow model, and a 1-D advection-diffusion heat flow model (Fig. 9). The model takes as inputs surface temperature, snow accumulation rate, geothermal heat flux at the ice/ rock interface and ice thickness. Temperature-dependent density and viscosity of ESTISOL were computed and used as inputs to the Darcy-Weisbach equation to predict fluid pressure as a function of depth (Fig. 10).

Note that a major source of uncertainty in the calculation stems from the position of the drill pipe in the borehole - if it is centered, pressure losses are approximately twice as severe as if the pipe lays on the wall (Piercy and others, 1933). Experienced drillers report that pipe generally lays on the wall (C. Delahunty, personal communication, 2013). To some extent the risk of hole closure can be mitigated by overpressuring the fluid at the surface injection point, but this pressure must not exceed the hydrofracture strength of polar glacial ice, which we found to be 190 psig (1.3 MPa) in $-17^{\circ} \mathrm{C}$ ice during a recent test near McMurdo Station at the firn-ice transition. It is expected that the fracture strength of ice will be greater at the colder temperatures of the Antarctic Plateau $\left(-50^{\circ} \mathrm{C}\right)$, but no tests have been done at lower temperature to our knowledge.

The opposite risk, of 'ballooning' the borehole in warm soft ice, occurs when fluid circulation is stopped and the fluid pressure returns to its static value (Fig. 10). Due to the fact that the firn is less dense than ESTISOL 140, the static pressure is always overpressured with respect to the ice while the fluid column extends all the way to the surface. After drilling, the fluid level will be lowered to closely balance the borehole pressure with the ice hydrostatic pressure in the warm soft ice, to prevent borehole deformation. This will be accomplished by evacuating ESTISOL in the borehole to a level below the packer by pumping air to the diverter, thereby forcing drilling fluid upward within drill rods to the fluid recirculation system for recovery. After removing the drill rods, the packer will be deflated and removed along with the primary casing. To prepare the boreholes for future down-hole observation, new plastic casing will be installed to the packer depth, capped and backfilled with snow to seal the annular space. Calculations show that the final fluid level needed for long-term borehole stabilization will be near the firn-ice transition.

\section{MODE OF OPERATION}

Once it is fully tested and deployed, the RAID drilling platform will become a community asset within the US Antarctic Program, with field operational management and maintenance to be provided by the University of Minnesota-Duluth. During sustained science operations, RAID will operate by traversing from McMurdo Station to field sites in East Antarctica, visit multiple drill sites and return to South Pole and/or McMurdo for winter-over. South Pole is a likely permanent logistics hub for the RAID platform because it is a major operational base on the ice cap that provides a machine shop, repair facility, medical staff, regular flights to and from McMurdo and is the inland 


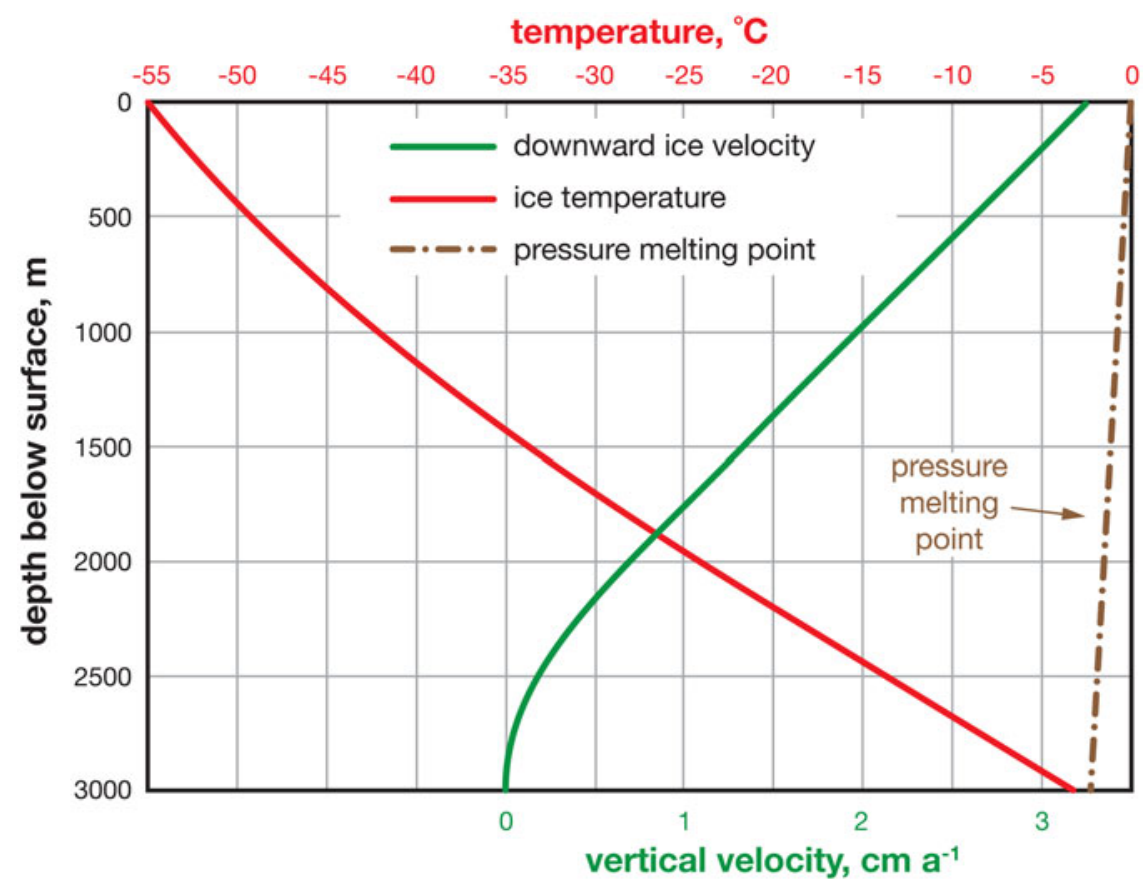

Fig. 9. Modeled steady-state temperature and velocity profiles at an East Antarctic plateau RAID site. Ice thickness is assumed to be $3000 \mathrm{~m}$, geothermal heat flux of $50 \mathrm{~mW} \mathrm{~m}^{-2}$, mean annual surface temperature of $-55^{\circ} \mathrm{C}$ and snow accumulation rate of $3 \mathrm{~cm} \mathrm{a}$ of water equivalent.

destination of over-ice traverses with heavy-lift capability. The rig and support equipment will be transported to South Pole by a combination of over-ice traverse vehicles and airlift. RAID traverses will depart South Pole each austral summer for continuous drilling operations at individual sites on the polar ice cap, then return to South Pole and/or McMurdo for the winter to make any needed repairs/modifications and prepare equipment for the next season's work.

To the extent possible, the RAID system is designed to be lightweight, compact, weather tight, energy efficient and operable by a small crew. It will be mobile and autonomous (Fig. 3), consisting of modularized and traversable

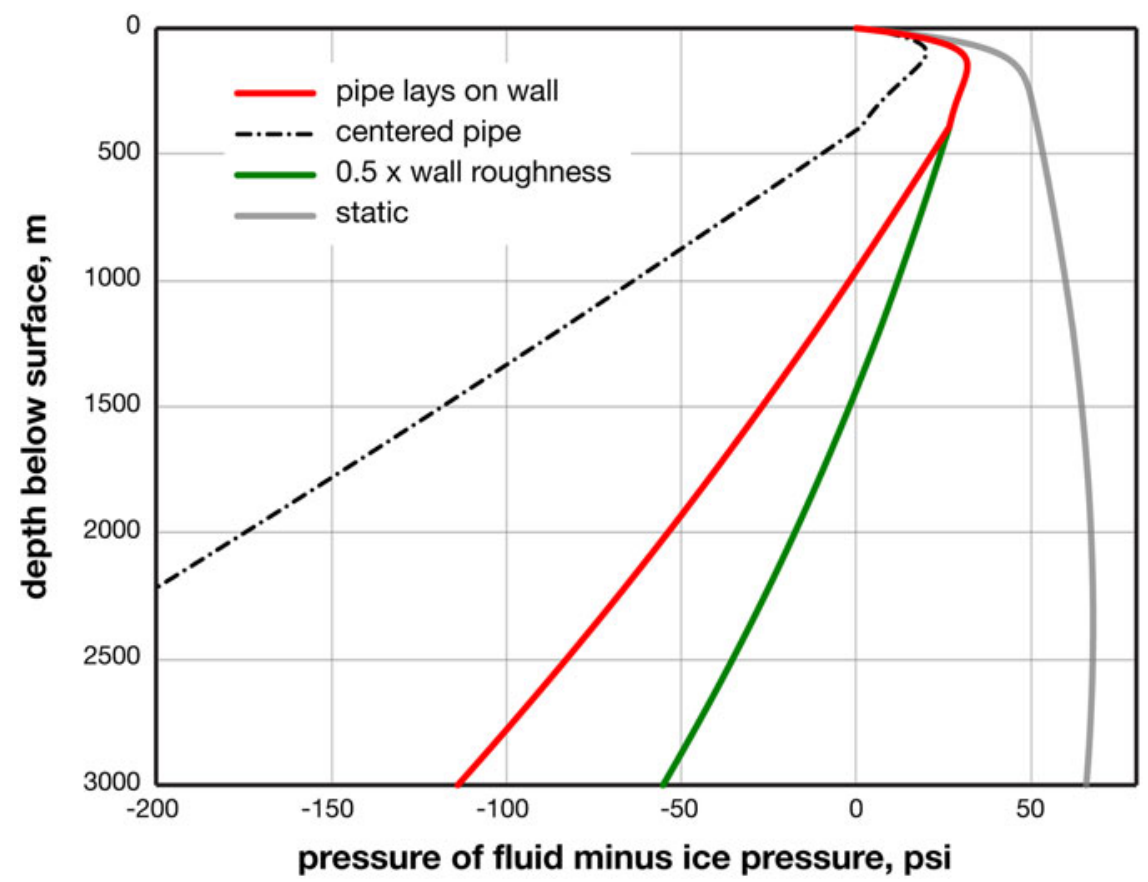

Fig. 10. Modeled dynamic pressure losses for a typical RAID hole, expressed as the difference between fluid pressure and ice hydrostatic pressure. Thus, a negative value indicates that the borehole will tend to close. During operations, the surface injection pump (Bean pump) and/or the airlift will be used to compensate for the differences shown here. Static curve shows pressure differences when fluid is not flowing. Assumptions: 30 gal $\mathrm{min}^{-1}\left(113.6 \mathrm{l} / \mathrm{min}^{-1}\right)$ fluid flow; $3.5 \mathrm{in}(8.9 \mathrm{~cm})$ hole diameter; 2.75 in $(7.0 \mathrm{~cm})$ pipe O.D.; $0.0057 \mathrm{~m}$ wall roughness; Darcy-Weisbach formulation; Re $>2300$ (turbulent); $50 \mathrm{~mW} \mathrm{~m}{ }^{-2}$ geothermal flux; $-55^{\circ} \mathrm{C}$ mean annual surface temperature; $2 \mathrm{~cm} / \mathrm{a}$ w.e. snow accumulation; ESTISOL 140 drilling fluid. 
components that will be towed in series by tractors to carry all structures and materiel required for berthing, supply and drilling. Minor consumable supplies, spare parts and personnel exchanges will be transported to and from the platform by light fixed-wing aircraft not requiring a groomed ski-way. Any major equipment will be transported to South Pole by fixed-wing or traverse vehicle. Because of its mobility and small footprint, RAID is not designed as a logistics hub for other projects.

For use as a research instrument, the targeting of drilling sites and subsequent access to the boreholes for down-hole observation are an important part of achieving the interdisciplinary goals established for RAID. The acquisition of airborne and over-snow geophysical imaging (ice-penetrating radar, aeromagnetics and aerogravity) is crucial for reconnaissance mapping of potential targets of old ice and subglacial geology. Reconnaissance geophysical mapping will therefore provide critical input for sensible site selection for RAID drilling, as well as for site safety surveys to determine subglacial conditions of ice thickness, basal layer composition and presence of water. A site-selection committee will review suggestions for future drilling sites based on scientific priorities and site characteristics. Borehole logging, both in reconnaissance fashion at the time of drilling and for detailed, high-resolution records after drilling is complete, is a key part of making RAID boreholes available as a research observatory. Borehole data acquisition will include optical logging of ice stratigraphy, ice crystallographic anisotropy, borehole deformation, temperature profiles, basal heat flow and bedrock orientation and in-situ stress. By bottoming in bedrock, RAID also has potential for long-term deep deployment of geophysical instrumentation.

Field drilling operations will normally take place in the general sequence listed in Box 3. A 12-15-person crew will travel with the drilling system. Personnel will consist of two or three 3-person drilling crews in order to maintain drilling operations for at least 16 hours $\mathrm{d}^{-1}$. Each drilling crew will consist of a principal driller and two assistants, all under the direction of a Lead Driller. In addition to the drilling crews, the field team will include a mechanic, a field coordinator (responsible for general camp duties, communications, weather observations, etc.) and science staff (responsible for receiving and handling samples, as well as general camp duties). All of the crew members will participate in day-to-day operations, including driving of the traverse vehicles. At least one crew member will be a certified medical first-responder or emergency medical technician.

\section{PROGRESS AND STATUS}

RAID development is divided into three phases, with major milestones of the project as listed in Table 3. Phase 1 entailed completion of a comprehensive design for an integrated drilling system, including buildable engineering diagrams, testing and deployment plans, and a detailed budget and construction schedule. Design of RAID began in March, 2013 and was completed by December that year.

Phase 2 of the project entails construction, assembly and testing of the RAID drilling platform in North America, followed by field trials in Antarctica and staging for future scientific operation on the East Antarctic ice sheet. Construction of the RAID system began in August 2014. Our first integrated field tests of the drill and fluid recirculation system were

Box 3. RAID operational sequence.

(1) Traverse safely to the drilling site with tractors and sleds

(2) Prepare the drilling site (snow leveling and compacting)

(3) Set up RAID system (laying out rig mats, positioning system over mats, lining up containers, connect all components, assemble components at the connection of the rig and rod racks, raise canopy, etc.)

(4) Power up and making all utility connections

(5) Rig up drilling mast

(6) Auger the firn

(7) Install casing, packer, and wellhead, then pressurize the hole

(8) Drill ice borehole to near bed

(9) Retrieve short ice cores

(10) Borehole video inspection and hole bottom temperature measurement

(11) Penetrate bed if ice is below freezing point and retrieve rock cores

(12) Pull drill string out

(13) Borehole optical logging; measurement of pressure, temperature, diameter and shape

(14) Rig down the system and prepare to mobilize

(15) Stabilize borehole with drilling fluid

(16) Mobilize and traverse to next site(s)

(17) Redeployment to fixed base for winterization

completed in early 2015 in the mountains near Bear Lake, Utah. Since then, additional fabrication and testing continued through 2015, capped by integration and validation

Table 3. Design, construction and deployment schedule

2012

2013

2014

2015

2016/17

2018/19

2019/20
Phase 1 engineering and design study funded Drilling system design work begins

Final design report issued

Phase 2 construction and testing funded

Construction, fabrication and testing of key systems begins

North American winter test at high elevation (Utah) completed

Continued fabrication, integration and validation tests Commissioning and readiness for Antarctic field trials

Delivery to Pt. Hueneme and vessel shipment to McMurdo Station

Antarctic field trials in McMurdo area

Traverse to South Pole and plateau field trials

RAID platform available for scientific drilling via South Pole (Phase 3)

Note: items in italics are planned. 
testing in Salt Lake City from August to November 2015. The completed drilling system was transported to California for vessel loading and shipment to Antarctica in late 2015. After off-loading in early 2016 and winterization, the rig will be deployed for field trials in the 2016/17 austral field season in order to validate its operational readiness for future science drilling (Phase 3).

\subsection{North American test}

In early 2015, we completed a system-level field test of the RAID drilling system in Utah (North American Test, NAT), which demonstrated the ability of RAID to drill through ice and take core with its principal components consisting of the drilling rig, fluid recirculation system and bottom-hole assembly. A site in the mountains of Utah was chosen because of historically cold temperatures, high elevation, low terrestrial heat flow and proximity to the DES facilities in Salt Lake City. All components of the RAID system functioned successfully as designed, and we demonstrated the capability of the drilling rig and fluid recirculation system to drill ice and take core in cold-weather, high-altitude field conditions. In support of the field tests completed in Utah, we also undertook a comprehensive set of bench tests and computational fluid dynamics modeling studies that validate key components of the RAID system and the drilling process.

In order to test the drilling and fluid-processing functions of RAID in an environment that is as close as practical to that expected in Antarctica, we first designed and implemented a unique cryogenically-cooled drilling test facility to make a column of ice by freezing water with liquid $\mathrm{CO}_{2}$. This method was implemented at a test facility at an elevation of $1824 \mathrm{~m}$ near Bear Lake, Utah, in early 2015. As summarized by Nielson and others (2015, in review), the general design of the NAT well consisted of a 10.75 inch $(27.3 \mathrm{~cm})$ outer casing cemented in a hole to a depth of $152 \mathrm{~m}$. Within that casing, we hung a 5.5 inch $(14.0 \mathrm{~cm})$ casing string within which a column of ice was formed by circulating a refrigerant in the annulus between the 5.5 and 10.75 inch casings. A thermistor string was installed in the annular space between the two casing strings to monitor temperatures at $15 \mathrm{~m}$ intervals. We used liquid $\mathrm{CO}_{2}$ as a refrigerant because it exists as a multi-phase material to low temperatures (triple point of $-57^{\circ} \mathrm{C}$ at $5.1 \mathrm{~atm}$, or $5.2 \times$ $10^{5} \mathrm{~Pa}$ ) and it is easily circulated, inexpensive and readily available. In order to minimize the likelihood of the casing splitting due to the volume increase associated with freezing water, the hole was cooled first and then ice was formed in increments from the bottom upward. Refrigeration of the ice column yielded down-hole temperatures of -20 to $-30^{\circ} \mathrm{C}$ to a depth of $137 \mathrm{~m}$.

During the NAT, we successfully demonstrated most of the technical requirements for RAID, including: (a) borehole penetration rates of up to $2.3 \mathrm{~m} \mathrm{~min}^{-1}$ (design limit of the LF230 rig), which corresponds to $<24$ hours to cut $3300 \mathrm{~m}$ not including drill rod cycling; (b) cutting a continuous 3.5 inch $(8.9 \mathrm{~cm})$ borehole; (c) successful operation of the drilling fluid recirculation system for ice chip removal and chip disposal at borehole temperatures similar to those we will encounter in Antarctica; (d) taking cores of ice and 'rock' (represented by cement) using the bottom-hole coring assembly; (e) mobility of the containerized modules; (f) operation of the drilling system with a crew of three; and (g) effective use of ESTISOL 140 as a drilling fluid at high elevation and cold air temperature. We were able to meet these requirements because of the combined capabilities of the drilling rig and effectiveness of the fluid recirculation system to keep pace with the production of ice cuttings. The main parameters that have a direct effect on penetration rate are: rotation speed (rpm) of the drill head; flow rate (gpm) of the fluid circulation system; the capacity of the fluid recirculation system to process debris and ice cuttings and return a clean drilling fluid; pressure exerted on the borehole to maintain the fluid flow required; and cutting capacity of the drill bit. All drill bit configurations worked as expected, and we experienced very even cutting and uniform fluid pressures in zones of clear, well-formed ice; similar cutting performance is expected in homogeneous Antarctic ice. Rotation rates during drilling were varied from 200 to $600 \mathrm{rpm}$, but we found that an ideal performance was achieved at 400-500 rpm and pumping ESTISOL at 20-25 gal min ${ }^{-1}$ (75-95 I $\min ^{-1}$, about half the maximum rate anticipated), thereby significantly reducing flow rate through the fluid recirculation system. The BHA worked as expected and rock-coring system yielded recovery of short cement cores at the base of the casing. The main functions yet to be tested include boosting our maximum cutting rates (up to $3 \mathrm{~m} \mathrm{~min}^{-1}$ ) and use of the air-lift system to manage fluid circulation in deep boreholes, both of which require deployment of the system to Antarctica. At deeper levels planned for Antarctica, greater weight on bit should support optimal cutting rates. Once a drilling routine was established at the NAT, we achieved a cycle time for $9 \mathrm{~m}$ long drill rods of $\leq 5 \mathrm{~min}$, which supports drilling to a depth of $3300 \mathrm{~m}$ in $<48$ hours.

\subsection{Antarctic field trials (AFT)}

We are currently planning a set of AFT for the 2016/17 austral summer in order to validate our operational plan, evaluate full integration of the drilling system in a deep-ice setting and learn from drilling operations in order to fully prepare for science drilling as an autonomous, traverse-capable system. Antarctica is the only place to effectively integrate the entire drilling system and evaluate the capability of those components designed for operation in thick firn and ice. In order to prove out the operational capacity of the RAID system, the goals for our proposed field trial include traversing over snow, site set-up, augering of firn and installation of casing, drilling through thick ice, retrieving ice and rock cores, rigging down, stabilizing the borehole and redeploying to a base station. The AFT will be conducted in the McMurdo Station operational area at a site of thick, grounded ice in order to take advantage of the established US Antarctic Program transport and logistics system, thereby reducing risk, cost and footprint in Antarctica. This approach represents the most logical, logistically light and cost-effective way to evaluate the full operational capability of the RAID system.

\section{SUMMARY}

We are designing, fabricating and testing a new RAID for use on the ice sheets of Antarctica. Our goal is to rapidly drill to deep ice (drilling penetration up to $3300 \mathrm{~m}$ depth), followed by coring of ice, ice-sheet bed interface, and bedrock substrate below. This new technology will provide a critical first look at the interface between major ice caps and their subglacial geology. As a mobile system, RAID offers direct access to deep ice, glacial bed and subglacial geology at 
multiple sites and leaves behind a 3-D array of legacy boreholes. RAID is unique because it can provide fast borehole access through thick ice; take short ice cores for paleoclimate study; sample the glacial bed to determine ice-flow conditions; take cores of subglacial bedrock for age dating and crustal history; rapidly date the ice via optical logging; and create boreholes for use as an observatory in the ice sheets. The RAID drilling platform will thus give the scientific community access to a rich record of geologic and climatic change on a variety of timescales, from the billion-year rock record to thousand-year ice and climate histories. As such, RAID is interdisciplinary and will allow access to polar paleoclimate records in ice $>1 \mathrm{Ma}$ to probe the cause of the mid-Pleistocene transition, permit direct observation at the base of the ice sheets and enable recovery of rock cores from the ice-covered East Antarctic craton to study its geotectonic evolution. This novel drilling technology will thus provide an entirely new way to obtain in situ measurements and samples of ice, glacial bed and rock for interdisciplinary studies in geology, glaciology, paleoclimate, microbiology and astrophysics.

\section{ACKNOWLEGEMENTS}

We thank the staff of DOSECC Exploration Services, LLC, the principal contractor for the design-build process of RAID development. We are particularly grateful for the efforts of Chris Delahunty, lead engineer on the project, along with Chad Clarke, John Eckels, Dan McClellan, Dennis Nielson and Philippe Wyffels. The RAID design team also included Gary Clow and Arnold Law. Mary Albert, Alfred Eustes, Michael Gerasimoff and Jay Thiessen provided valuable insight and encouragement during the concept scoping phase, and Steffen Bo Hansen provided a review of the completed conceptual design. Steffen Bo Hansen measured the ESTISOL 140 viscosity at Antarctic temperatures and generously shared the data with us. We appreciate input from IDDO engineers Chris Gibson, Jay Johnson, and Tanner Kuhl, and help with validation by Frank Rack. John Rashid and Blaise Stephanus have capably guided the project management. Matthew Kippenhan has provided excellent support in the design and operational support planning. The RAID development project is supported by the Division of Polar Programs at the US National Science Foundation with awards to Goodge (1242027 and 1419935) and Severinghaus (1242049 and 1419979). We thank two anonymous reviewers for their helpful recommendations.

\section{REFERENCES}

Augustine NR and 11 others (2012) More and better science in Antarctica through increased logistical effectiveness. U.S. Office of Science and Technology Policy and the National Science Foundation, Washington DC, $28 \mathrm{pp}$

Clow GD and Koci B (2002) A fast mechanical-access drill for polar glaciology, paleoclimatology, geology, tectonics, and biology. Mem. Natl. Inst. Polar Res., 56, 5-37

Dansgaard W and Johnsen SJ (1969) A flow model and a time scale for the ice core from Camp Century, Greenland. J. Glaciol., 8, 215-223
DeConto RM and Pollard D (2003) Rapid Cenozoic glaciation of Antarctica induced by declining atmospheric $\mathrm{CO}_{2}$. Nature, 421, 245-249 (doi: 10.1038/nature01290)

Fischer $\mathrm{H}$ and 29 others (2013) Where to find 1.5 million yr old ice for the IPICS "Oldest-Ice" ice core. Clim. Past, 9, 2489-2505 (doi: 10.5194/cp-9-2489-2013)

Fretwell P and 59 others (2013) Bedmap2: improved ice bed, surface and thickness datasets for Antarctica. Cryosphere, 7, 375-393 (doi: 10.5194/tc-7-375-2013)

Gerasimoff MD (2012) Prospectus for a Rapid Access Ice Drill: A drilling system equipped for rapid transit of glacial ice, equipped for on-the-fly ice coring and subglacial rock coring, and suitable for regional geological mapping and glaciology. Ice Drilling Design and Operations report, University of Wisconsin, Madison, Wisconsin, $57 \mathrm{pp}$

Goodge JW and Finn CA (2010) Glimpses of East Antarctica: Aeromagnetic and satellite magnetic view from the central Transantarctic Mountains of East Antarctica. J. Geophys. Res., 115, B09103 (doi: 10.1029/2009JB006890)

Goodge J and 8 others (2011) RAID: Rapid Access Ice Drilling. Ice Drilling Program Office Workshop Report, Herndon, Virginia, April 15-16, 3 pp

Harley SL, Fitzsimons ICW and Zhao Y (2013) Antarctica and supercontinent evolution: historical perspectives, recent advances and unresolved issues. In Harley SL, Fitzsimons ICW and Zhao Y, eds. Antarctica and supercontinent evolution, vol. 383. Geological Society, Special Publications, London, 1-34 (doi: 10.1144/ SP383.9)

Herron MM and Langway CC, J. (1980) Firn densification: an empirical model. I. Glaciol., 25, 373-385

Lisiecki L and Raymo M (2007) Plio-Pleistocene climate evolution: trends and transitions in glacial cycle dynamics. Quat. Sci. Rev., 26, 56-69 (doi: 10.1016/j.quascirev.2006.09.005)

Nielson DL, Delahunty C, Goodge J and Severinghaus JP (2015) Facility for testing ice drills. Sci. Drill., in review

Piercy NAV, Hooper MS and Winny HF (1933) Viscous flow through pipes with core. Philos. Mag., 15, 647-676 (doi: 10.1080/ 14786443309462212)

Raymo ME, Lisiecki LE and Nisancioglu KH (2006) Plio-Pleistocene ice volume, Antarctic climate, and the global $\delta^{18} \mathrm{O}$ record. Science, 313, 492-495 (doi: 10.1126/science.1123296)

Rignot E, Mouginot J and Scheuchl B (2011) Ice flow of the Antarctic ice sheet. Science, 333, 1427-1430 (doi: 10.1126/ science.1208336)

Ritzwoller MH, Shapiro NM, Levshin AL and Leahy GM (2001) Crustal and upper mantle structure beneath Antarctica and surrounding oceans. J. Geophys. Res., 106, 30,645-30,670 (doi: 10.1029/2001JB000179)

Sheldon SG, Popp TJ, Hansen SB and Steffensen JP (2014) Promising new borehole liquids for ice-core drilling on the East Antarctic high plateau. Ann. Glaciol., 55(68), 260-270 (doi: 10.3189/ 2014AoG68A043)

Van Liefferinge B and Pattyn F (2013) Using ice-flow models to evaluate potential sites of million year-old ice in Antarctica. Clim. Past, 9, 2335-2345 (doi: 10.5194/cp-9-2335-2013)

Wilson DS and 5 others (2011) Antarctic topography at the EoceneOligocene boundary. Palaeogeogr. Palaeoclimatol. Palaeoecol. 335-6, 24-34 (doi: 10.1016/j.palaeo.2011.05.028)

Zachos JC, Quinn TM and Salamy K (1996) High resolution $\left(10^{4}\right.$ yr) deep-sea foraminiferal stable isotope time series. Paleoceanography, 11, 251-266 (doi: 10.1029/96PA00571)

Zapol WM and 17 others (2011) Future science opportunities in Antarctica and the Southern Ocean. National Research Council, National Academies Press, Washington, D.C., 195 pp 